International Journal of Physical Sciences and Engineering
Available online at http://sciencescholar.us/journal/index.php/ijpse
Vol. 2 No. 3, December 2018, pages: 70 76
e-ISSN : 2550-6943, p-ISSN : 2550-6951
https://doi.org/10.29332/ijpse.v2n3.231

\title{
Pre and Post Mount Merapi Eruption of Free Air Anomaly in
} 2010

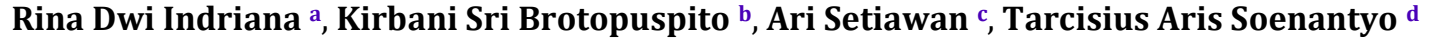

Article history: Received 9 April 2018, Accepted: 30 August 2018, Published: 13 December 2018

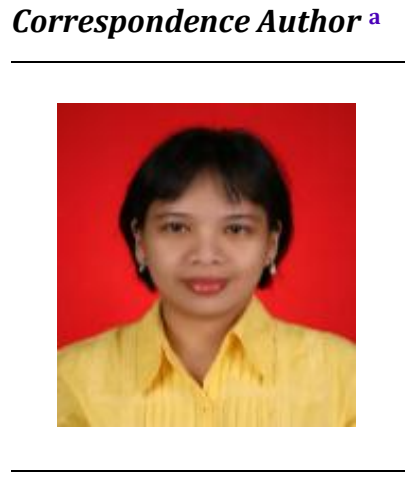

\section{Keywords}

2010 eruption; free air anomaly; mount merapi; topographic; volcano;

\begin{abstract}
Mount Merapi eruption in 2010 was one type of eruption with large scale during the last 100 years. Eruptions that was occurred resulting topographic changes in the peak of Mount Merapi, and the possibility of changing the subsurface structure. The research was part of a large study that has been conducted to assess the subsurface changes of pre-and post-eruption of Mount Merapi in 2010. The study discussed observations of free air anomalies pre and after the 2010 eruption. There were grouped into three periods. Processing of air anomalies was free to use using the $2^{\text {nd }}$ orde calculation method. The results obtained were the changes in the contours of the FAA Mount Merapi in 1988, 1998, and 2011 as a result of topographic changes that occurred in the peak area and the alleged dynamics of the surface. The dynamics at Mount Merapi in the 1988 to 2011 period occurred in the northwest, southeast, east, and northeast of the study area and southeast of the peak of Mount Merapi.
\end{abstract}

e-ISSN: 2550-6943, p-ISSN: 2550-6951 ${ }^{\circ}$ Copyright 2018. The Author. SS Journals Published by Universidad Técnica de Manabí. This is an open-access article under the CC BY-SA 4.0 license (https://creativecommons.org/licenses/by-sa/4.0/) All rights reserved.

\section{Contents}

Abstract 70

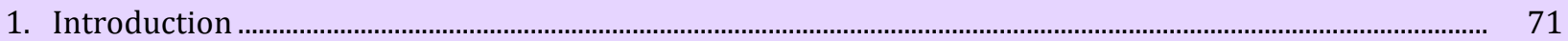

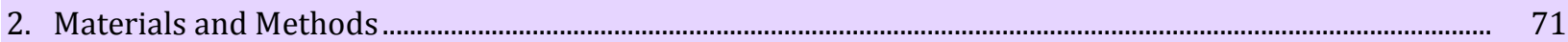

3. Results and Discussions ............................................................................................................................................... 72

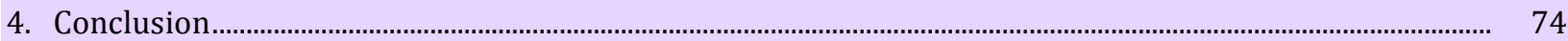

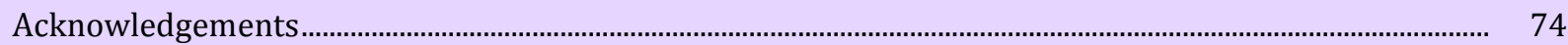

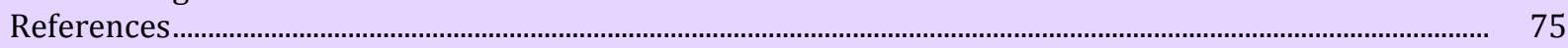

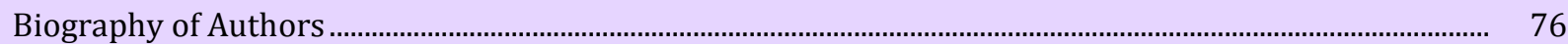

a Department of Physics, Universitas Diponegoro, Semarang, Indonesia

b Geophysics Study Program, FMIPA, Universitas Gadjah Mada, Yogyakarta, Indonesia

c Geophysics Study Program, FMIPA, Universitas Gadjah Mada, Yogyakarta, Indonesia

d Geodesy Techniques FT, Universitas Gadjah Mada, Yogyakarta, Indonesia 


\section{Introduction}

Mount Merapi eruption in 2010 reached a scale of 4 VEI (Volcanic Explosivity Index) (Carr et al., 2016). VEI is a relative measure of the eruption strength at Merapi eruption, or it can be understood as a large-scale quantitative eruption based on the amount of material released during eruption and column height during eruptions (Newhall \& Self, 1982). Information about the activities and dynamics of Merapi eruption is important to study in order to obtain Merapi characteristics. Merapi eruption in 2010 was one type of eruption with large scale during the last 100 years. Eruptions were occurred resulting topographic changes in the peak of Mount Merapi, and the possibility of changing the subsurface structure. Strengthening allegations of changes in subsurface structure due to Merapi eruption in 2010, followed by small eruptions without preceding signs/phases, both eruptions caused by the volcanic activity of Mount Merapi and from ongoing tectonic activities. The research conducted is part of a large study conducted to observe the changes in the subsurface pre and post-eruption in 2010. In this study an observation of the value of free air anomaly.

\section{Materials and Methods}

The primary data are gravitational field data and GPS data. Gravitational field data Merapi from 1988 to 2011 consisting of secondary data from the 1986 to 1989 gravitational field measurements (Nesvizhevsky et al., 2000; Diosi, 1987; DeWitt \& Brehme, 1960). The data in 1997 to 2000 gravitational field measurement data Sunantyo \& Susanto (2008), with total data as many as 248 data in 1986 to 1989 as many as 130 secondary data as a result of 2011 to 2012 gravitational field measurements with the available 198 data. The supporting data used is DEM data. DEM data used for the 1987 period. 1989 is DEM data from aerial photographs in 1981. DEM data for the 1997 to 2000 period is the DEM data from Sandwell \& Smith (1997). Data 2011 to 2012 used DEM 2012 data from Lidar 2011 results obtained from the Volcanology Agency. The FAA calculation process in this study uses FAA 2. The calculation process is done using Matlab software.

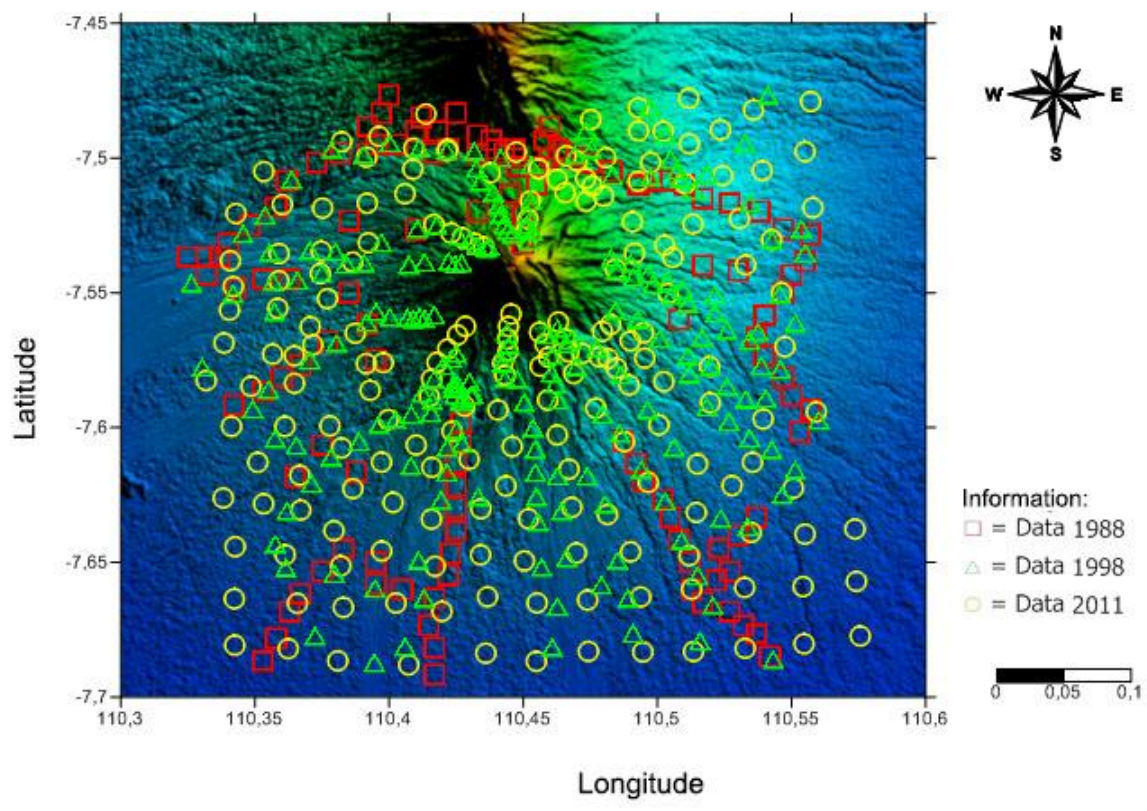

Figure 1. Distribution of measurement points in 1988, 1998, and 2011

Indriana, R. D., Brotopuspito, K. S., Setiawan, A., \& Soenantyo, T. A. (2018). Pre and post Mount Merapi eruption of free air anomaly in 2010. International Journal of Physical Sciences and Engineering, 2(3), 70-76. https://doi.org/10.29332/ijpse.v2n3.231 
Theory

Torge (1989), explained that the next theoretical gravitational field correction is a correction that takes into account the height of the observation point. The mathematical equation for the correction of free air according to Heiskanen \& Moritz (1967):

$$
F A=-\left(0,30877-0,0045 \sin ^{2} \varphi\right) h+0,000072 h^{2}
$$

In fact, the earth shape is closer to the ellipsoid and as and Newton (2013), explained that the attraction between particles is inversely proportional to the square of the distance. As a result, a second order free air correction formula is needed (Li \& Gotze, 2001):

$$
F A=-\left(0,3087691-0,0004398 \sin ^{2} \phi\right) h+7,2125 \times 10^{-8} h^{2} M g A l
$$

Based on FA is a free air correction, $\phi$ is latitude and $h$ is the height of the observation point of $z=0$. The anomaly of the free air gravitational field at the observation point, $\Delta g_{f a}$ is formulated:

$$
\Delta g_{f a}=g_{m}-\left(g_{n}+F A\right)
$$

Description:

$\Delta g_{f a}$ : Free Air Anomaly (FAA)

$g_{m} \quad$ : absolute gravitational field value at the point of observation

$g_{n} \quad$ : normal gravitational field value in the spheroid reference field

FA : correction of free air at the observation point (Li \& Gotze, 2001; Simpen et al., 2017)

\section{Results and Discussions}

The results of processing using orde 2 free air correction are as shown in Figure 2. Free air anomalies in 1988,1998 , and 2011 have contour patterns that are almost equal to the FAA value of $50 \mathrm{MgAl}$ to $100 \mathrm{MgAl}$ in the east and northwest of the research area and in the peak Merapi area of value of free air anomaly is 175 $\mathrm{MgAl}$ to $260 \mathrm{MgAl}$. To facilitate FAA values can be grouped into three, i.e., groups of low anomalous values 50 $\mathrm{MgAl}$ to $100 \mathrm{MgAl}$ is represented by purple to dark blue, medium anomaly of $101 \mathrm{MgAl}$ to $175 \mathrm{MgAl}$ is represented by light blue to green and high anomaly at $176 \mathrm{MgAl}$ to $256 \mathrm{MgAl}$ is represented by yellow to pink.

FAA in 1988 was mapped as in Figure 2a with dark blue contours-purple is in the southwest to the northeast with a minimum value in the southeast to the northeast. Low anomalies also appear in the west and northwest towards the peak of Merapi. Medium anomalies which are blue to green form a pattern from the south around Merapi and continue southwest and north. High anomalies exist around the peak continuously to the north of Anomaly high around the peak of Merapi at an elevation of $1400 \mathrm{~m}$ and in the southeast at an elevation of $1700 \mathrm{~m}$. Figure $2 \mathrm{~b}$ is a picture of the FAA contour map in 1998, maps dark blue-purple showing a pattern from southeast to northeast with a minimum value in the east to northeast and in the northwest. High anomalies are in the peak area. The high anomaly at the peak of Merapi starts from an elevation of $1400 \mathrm{~m}$ towards the top. The changes in anomalies in the southeastern peak area at an elevation of $1400 \mathrm{~m}$ appear to have changed the original yellow color in 1988 to green in 1998. Mapping the subsequent FAA values for data for 2011 is illustrated in Figure 2c, with the contour color distribution as follows: dark blue to purple contours form a pattern from the northwest and northeast with a minimum value in the southeast to the northeast and west to the northwest towards the peak of Mount Merapi. The blue contour appears from the north to form a pattern around Mount Merapi and continues to the south. The high anomaly in the peak area of Mount Merapi starts from the elevation of $1400 \mathrm{~m}$ towards the peak. 


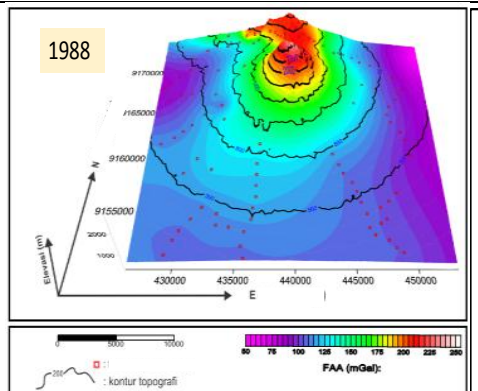

a

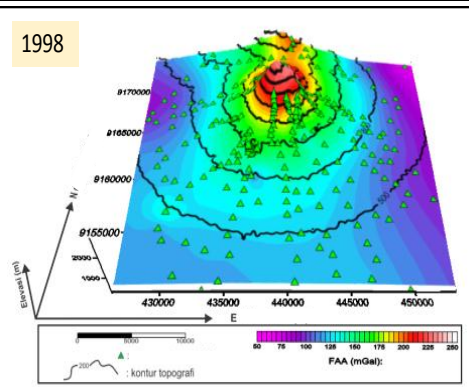

b

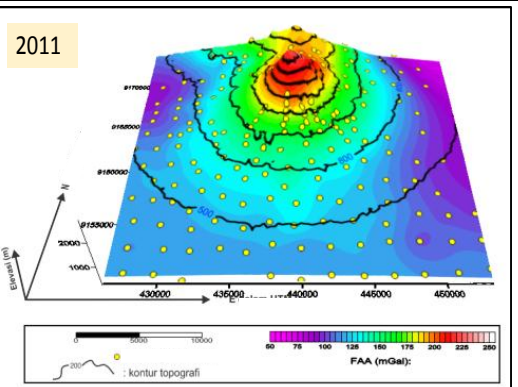

C

Figure 2. Map of topographic contours of free air anomalies (a)1988, (b) 1998, (c) 2011

If the three FAA figures are compared, the following results are obtained: the area observation of purple anomalous contours in the northwest indicates that the purple contour in 1988 was the most extensive compared to the area of 2011 and 1998. Other purple contours exist in the southeast to the northeast, which 1988 was the widest area compared to 2011 and 1998. The blue to green contours showed changes in the southwest and south. In 1988, the blue to green contour patterns appeared from the north around Merapi and continued southwest. The area of anomalous regions blue in 1988 was the narrowest compared to the same color area in 2011 and 1998. The light blue contour pattern in 1998 was the widest. Therefore, it could be analyzed from 1988 to 1998 an increase in the FAA value was then in 2011 and 1998 there was a decline in FAA values in the south, southwest and southeast. The green contour shows a change in the pattern in the southeastern southeast at an elevation of $1400 \mathrm{~m}$ to $2000 \mathrm{~m}$. The red contour area shows the change in pattern/area starting at the elevation of $1400 \mathrm{~m}$ towards the peak of Merapi. The high area anomaly in 1988 was the narrowest compared to 2011 and 1998. The changes in the red contour were seen in the southeast, namely at an elevation of $1700 \mathrm{~m}$ to $2400 \mathrm{~m}$. The extent of the high anomaly around the peak changes the area and direction.

Regarding the observed pattern changes it can be seen that the dynamics occurred at Merapi in the northwest, southeast, east, and northeast of the study area and southeast of the peak of Merapi. The calculation results of the free air anomalies in 1998 and 2011 can be seen that the value of free air anomalies has a value range of $50 \mathrm{MgAl}$ to $256 \mathrm{MgAl}$ as in Table 1 is a table of FAA values for three measurement periods. The value of free air anomalies in 1988 had the greatest range of values compared to free air anomalies in 1998 and 2011 with a maximum and minimum difference of FAA values of $\pm 204 \mathrm{MgAl}$, while the value range in 1998 was $\pm 183 \mathrm{MgAl}$ and $\pm 178 \mathrm{MgAl}$ for 2011. Table 1 shows the value of free air anomaly in 1988 had the lowest minimum value compared to the free air anomalies of 1998 and 2011, and the highest maximum value compared to 1998 and 2011. Referring to the changes in the height of peak of Merapi, with the height associated and dome growth lava, it is known that $h$ in 1988 was higher than in 1998 and 2011 peak morphological changes caused by the growth of lava domes which formed for some time before eruptions or changes occurred due to erosion in the peak area of Merapi.

The biggest dome growth occurred in the 1979 to 1985 period. Respecting the study on the growth of Merapi lava domes by Ika (2013), the following results were obtained: Mount Merapi showed the highest height increase in 1962 to 1979 at 90 meters to 115 meters, in 1979 to 1985 amounting to 90 meters to 115 , 1985, to 2012 amounted to 40 meters to 76 meters and after the eruption that occurred between 1985 to 2012 there was a reduction in height. The biggest reduction in height of the dome of Mount Merapi occurred in 1985 to 2012 which was marked by a reduction in the volume of Merapi dome by $17.871 .781,96 \mathrm{~m}^{3}$ and a decrease in height of 250 meters due to the large eruption that occurred in 2010 . The changes in the peak morphology and elevation of other measurement points will affect the free air correction value. Table 1 shows that the greatest FAA value occurred in the 1998 period which decreased in value in the period 2011. This is possible because in the peak area there was a significant change in elevation such as research conducted by Ika (2013), namely the growth of lava domes and dome collapse lava.

Indriana, R. D., Brotopuspito, K. S., Setiawan, A., \& Soenantyo, T. A. (2018). Pre and post Mount Merapi eruption of free air anomaly in 2010. International Journal of Physical Sciences and Engineering, 2(3), 70-76. https://doi.org/10.29332/ijpse.v2n3.231 
Table 1

Value of free air anomalies (Free Air Anomaly/FAA) and volcanic elevations

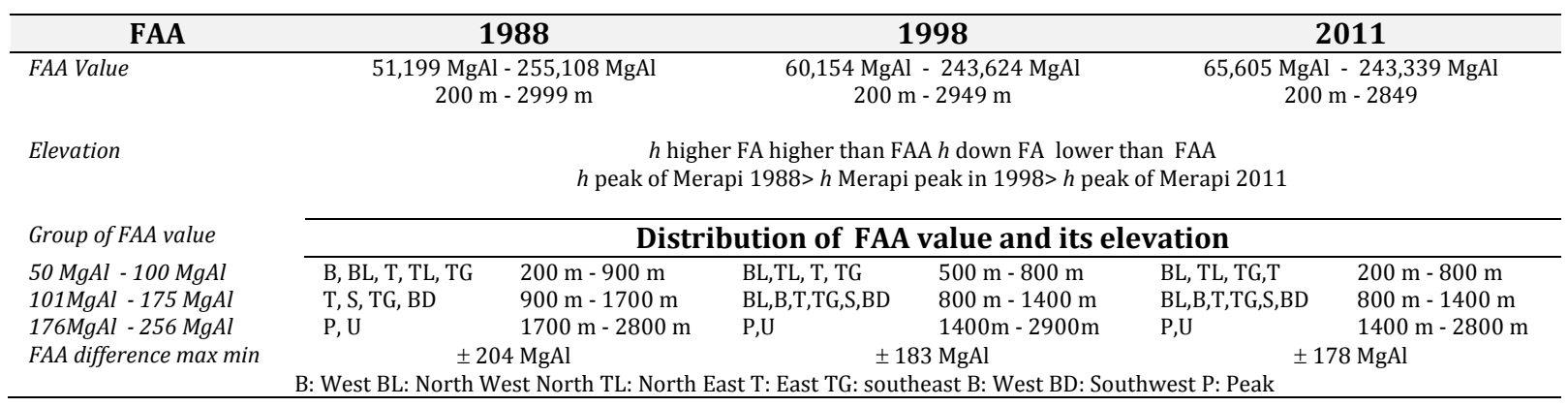

\section{Conclusion}

The FAA Merapi contour maps in 1988, 1998, and 2011 showed the changes in FAA values as a result of topographic changes that occurred in the peak area of Merapi and suspected subsurface dynamics occurred in the pre and post eruptions of 2010. The subsurface dynamics were thought to be in the northwest, southeast, the east and northeast of the research area and southeast of the peak of Merapi.

\section{Acknowledgments}

The authors would like to thank the UGM Geophysics laboratory for the 1988 to 2012 gravity data which is permitted to be reprocessed. 


\section{References}

Carr, B. B., Clarke, A. B., \& Vanderkluysen, L. (2016). The 2006 lava dome eruption of Merapi Volcano (Indonesia): Detailed analysis using MODIS TIR. Journal of Volcanology and Geothermal Research, 311, 6071. https://doi.org/10.1016/j.jvolgeores.2015.12.004

DeWitt, B. S., \& Brehme, R. W. (1960). Radiation damping in a gravitational field. Annals of Physics, 9(2), 220259. https://doi.org/10.1016/0003-4916(60)90030-0

Diosi, L. (1987). A universal master equation for the gravitational violation of quantum mechanics. Physics letters A, 120(8), 377-381. https://doi.org/10.1016/0375-9601(87)90681-5

Heiskanen, W. A., \& Moritz, H. (1967). Physical geodesy. Bulletin Géodésique (1946-1975), 86(1), 491-492. https://doi.org/10.1007/BF02525647

Li, X., \& Götze, H. J. (2001). Ellipsoid, geoid, gravity, geodesy, and geophysics. Geophysics, 66(6), 1660-1668. https://doi.org/10.1190/1.1487109

Maya Ika, K. (2013). Peta Pertumbuhan Kubah Merapi. Sekolah Vokasi Penginderaan Jarak Jauh. Universitas Gadjah Mada.

Nesvizhevsky, V. V., Börner, H., Gagarski, A. M., Petrov, G. A., Petukhov, A. K., Abele, H., ... \& Soloviev, S. M. (2000). Search for quantum states of the neutron in a gravitational field: gravitational levels. Nuclear Instruments and Methods in Physics Research Section A: Accelerators, Spectrometers, Detectors and Associated Equipment, 440(3), 754-759. https://doi.org/10.1016/S0168-9002(99)01077-3

Newhall, C. G., \& Self, S. (1982). The volcanic explosivity index (VEI) an estimate of explosive magnitude for historical volcanism. Journal of Geophysical Research: Oceans, 87(C2), 1231-1238. https://doi.org/10.1029/JC087iC02p01231

Newton, R. G. (2013). Scattering theory of waves and particles. Springer Science \& Business Media.

Sandwell, D. T., \& Smith, W. H. (1997). Marine gravity anomaly from Geosat and ERS 1 satellite altimetry. Journal of Geophysical Research: Solid Earth, 102(B5), 10039-10054. https://doi.org/10.1029/96JB03223

Simpen, I. N., Redana, I. W., Pujianiki, N. N., \& Umratul, I. (2017). Aquifers selection to aid geoelectrical methods on drilled well building near the beach. International Journal of Physical Sciences and Engineering, 1(3), 41-50. https://doi.org/10.21744/ijpse.v1i3.66

Sunantyo, T. A., \& Susanto, P. P. A. (2008). Modeling of local geoid using adaptive scheme:: A case study around Merapi and Merbabu volcanoes, Central Jawa, Indonesia.

Wahyudi, J. B. (1986). Media Komunikasi Massa Televisi. Alumni.

Indriana, R. D., Brotopuspito, K. S., Setiawan, A., \& Soenantyo, T. A. (2018). Pre and post Mount Merapi eruption of free air anomaly in 2010. International Journal of Physical Sciences and Engineering, 2(3), 70-76. 


\section{Biography of Authors}

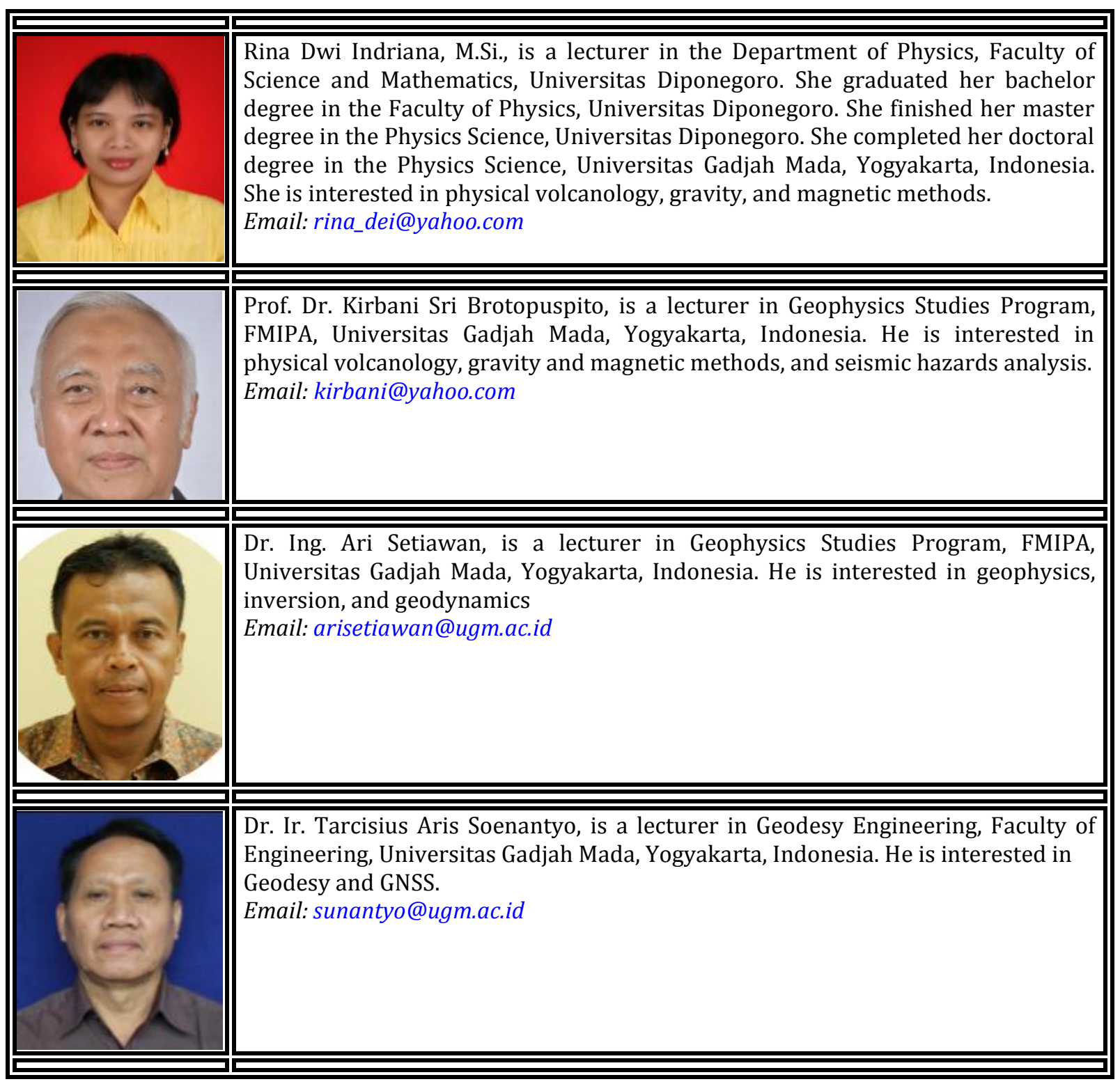

